\title{
Synthesis and Evaluation of New Phthalazine Urea and Thiourea Derivatives as Carbonic Anhydrase Inhibitors
}

\author{
Nurcan Berber, ${ }^{1}$ Mustafa Arslan, ${ }^{1}$ Emre Yavuz, ${ }^{2}$ Cigdem Bilen, ${ }^{2}$ and Nahit Gencer ${ }^{2}$ \\ ${ }^{1}$ Department of Chemistry, Faculty of Art and Sciences, Sakarya University, 54147 Sakarya, Turkey \\ ${ }^{2}$ Department of Chemistry, Faculty of Art and Sciences, Balikesir University, 10145 Balikesir, Turkey \\ Correspondence should be addressed to Nahit Gencer; ngencer@balikesir.edu.tr
}

Received 28 May 2013; Revised 2 August 2013; Accepted 2 August 2013

Academic Editor: Tanaji Talele

Copyright (c) 2013 Nurcan Berber et al. This is an open access article distributed under the Creative Commons Attribution License, which permits unrestricted use, distribution, and reproduction in any medium, provided the original work is properly cited.

\begin{abstract}
A new series of phthalazine substituted urea and thiourea derivatives were synthesized, and their inhibitory effects on the activity of purified human carbonic anhydrases (hCAs I and II) were evaluated. 2H-Indazolo[2,1-b]phthalazine-trione derivative (1) was prepared with 4-nitrobenzaldehyde, dimedone, and phthalhydrazide in the presence of TFA in DMF, and nitro group was reduced to amine derivative (2) with $\mathrm{SnCl}_{2} \cdot 2 \mathrm{H}_{2} \mathrm{O}$. The compound was reacted with isocyanates and isothiocyanates to get the final products $(3 \mathbf{a}-\mathbf{p})$. The results showed that all the synthesized compounds inhibited the CA isoenzymes activity. $3 \mathbf{a}\left(\mathrm{IC}_{50}=6.40 \mu \mathrm{M}\right.$ for hCA I and $6.13 \mu \mathrm{M}$ for hCA II) has the most inhibitory effect. The synthesized compounds are very bulky to be able to bind near the zinc ion, and they much more probably bind as the coumarin derivatives.
\end{abstract}

\section{Introduction}

The carbonic anhydrases (CAs, EC 4.2.1.1.) are commonly characterized as zinc metalloenzymes whose primary physiological function is to rapidly catalyze the reversible hydration of carbon dioxide to form bicarbonate and a proton [1]. CAs are ubiquitous enzymes present in prokaryotes and eukaryotes which are encoded by five known CA structural families, the structurally characterized $\alpha-, \beta$-, and $\gamma$-classes and the more recently discovered $\delta$ - and $\zeta$-classes [2]. The $\alpha$-CAs are found in vertebrates, algae, eubacteria, and cytoplasm of green plants whereas the $\gamma$-CAs are present mainly in Archaea and few eubacteria. The $\beta$-CAs are predominantly available in chloroplasts of mono- and dicotyledonous plants along with some algae and eubacteria. The $\delta$-CAs are primarily found in marine diatoms. In humans, 16 isoforms of $\alpha$-CAs have been reported, of which three are CARP or CA-related proteins [3]. There are sixteen isozymes which are characterized, and many of them are involved in critical physiological processes [4]. CAs are found in a variety of tissues such as kidneys, lungs, eyes, skins, the nervous systems, and the gastrointestinal tract in humans [5]. Biological activities of this metalloenzyme family have several medicinal applications which are commonly used as diuretics for the treatment of symptoms of hypertension [6], as antiglaucoma drugs [7], and for the treatment of high altitude sickness, gastric and duodenal ulcers, epilepsy, and osteoporosis [8]. More recently CA inhibitors have been shown to have potential as antiobesity drugs [9].

Majorities of the drugs used in human medicine are heterocyclic compounds. Common drugs such as Morphine, Lipitor, Penicillin, and nonsteroidal anti-inflammatory agents contain at least one heteroatom in their structure [10]. Heterocyclic compounds containing nitrogen group have large area in nature, and their utilization is becoming progressively important as biologically active pharmaceuticals, agrochemicals, and functional materials [11]. In particular, hydrazine containing heterocyclic compounds have been considered of great importance on account of pharmacological properties and clinical applications [12]. Moreover, these of combined phthalazines have biological properties such as inhibition of p38 MAP kinase [13] for selective binding of GABA receptor [14], antianxiety drug [15], antitumor agent [16], and highaffinity ligand to the a2d-1 subunit of calcium channel [17].

Phthalazine derivatives have been greatly used as therapeutic agents owing to their anticonvulsant, cardiotonic, 
<smiles>CS(=O)(=O)N1CCCC(Cn2nc(Cc3ccc(Cl)cc3)c3ccccc3c2=O)CC1</smiles>

Azelastin

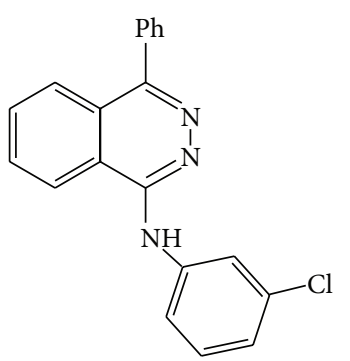

MY 5445

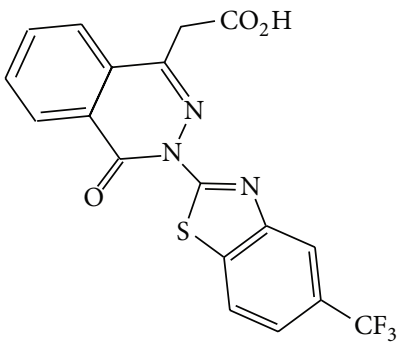

Zopolrestat<smiles>NNc1nncc2ccccc12</smiles>

Hydralazine<smiles>Nc1cccc2c(=O)[nH]nc(O)c12</smiles>

Luminol

Scheme 1: Some commercially used phthalazine derivatives.

vasorelaxant, anti-inflammatory properties [18-23], and antimicrobial activity [24]. Like azelastine, the phthalazine derivatives have antihistaminic effects in the treatment of allergic rhinitis [25], and hydralazine is used as antihypertensive agent in the treatment of pulmonary hypertension [26-28]. Some commercially used phthalazine derivatives are shown in Scheme 1.

Ureidosubstituted benzenesulfonamides show very interesting profile for the inhibition of several human carbonic anhydrases (hCAs) such as hCAs I and II (cytosolic isoforms) and hCAs IX and XII (transmembrane, tumor-associated enzymes). It is mentioned that the compounds have excellent inhibitory effects for all these isoforms due to the urea moiety [29]. On the other hand, it has been reported that some urea derivatives have CA inhibitor activities [30,31]. Therefore, the investigation of clinically useful ureas/thioureas is a growing field of interest. In this study, a new series of phthalazine substituted urea and thiourea derivatives were synthesized, and their inhibitory effects on the activity of purified human carbonic anhydrases (hCAs I and II) were evaluated.

\section{Experimental Procedures}

2.1. General. All starting materials and reagents were purchased from commercial suppliers. Reactions were monitored by TLC and TLC plates visualized with short wave UV fluorescence $(k=254 \mathrm{~nm})$. Melting points were taken on a Yanagimoto micromelting point apparatus and were uncorrected. IR spectra were measured on a SHIMADZU Prestige-21 (200 VCE) spectrometer. ${ }^{1} \mathrm{H}$ and ${ }^{13} \mathrm{C}$ NMR spectra were measured on spectrometer at VARIAN Infinity Plus 300 and at $75 \mathrm{MHz}$, respectively. ${ }^{1} \mathrm{H}$ and ${ }^{13} \mathrm{C}$ chemical shifts are referenced to the internal deuterated solvent. The mass spectrometry analysis was carried out with a ABSCIEX-4000 QTRAP LC-MS-MS instrument.

\subsection{Synthesis of $2 \mathrm{H}$-Indazolo[2,1-b]phthalazine-trione Deriva-} tive (1). A mixture of TFA $(0.5 \mathrm{~mL}), 4$-nitrobenzaldehyde $(1.0 \mathrm{mmol})$, dimedone $(1.0 \mathrm{mmol})$, and phthalhydrazide $(1.0 \mathrm{mmol})$ in DMF $(20 \mathrm{~mL})$ was stirred and refluxed at $90^{\circ} \mathrm{C}$ for 16 hours. After completion of the reaction, the mixture was allowed to be cooled to room temperature and poured on cold water $(50 \mathrm{~mL})$. The precipitate was filtered, washed with water, and dried. The product (2H-indazolo[2,1-b] phthalazine-trione) was purified washing with hot ether.

2.2.1. 3,3-Dimethyl-13-(4-nitrophenyl)-3,4-dihydro-2H-indazolo[1,2-b]phthalazine-1,6,11(13H)-trione (1). Yield 80\%, m.p. $350-352^{\circ} \mathrm{C} ;{ }^{1} \mathrm{H} \mathrm{NMR}\left(\mathrm{CDCl}_{3}, 300 \mathrm{MHz}, \delta, \mathrm{ppm}\right): 1.19(3 \mathrm{H}, \mathrm{s})$, 1.22 (3H, s), 2.34 (2H, s), 3.18-3.44 (2H, AB system, J: 19.21), $6.51(1 \mathrm{H}, \mathrm{s}), 7.59-7.62$ (2H, d, J: 8.7), 7.88-7.91 (2H, m), 8.19$8.22(2 \mathrm{H}, \mathrm{d}, J: 8.7), 8.23-8.27(1 \mathrm{H}, \mathrm{m}), 8.37-8.40(1 \mathrm{H}, \mathrm{m}) .{ }^{13} \mathrm{C}$ $\mathrm{NMR}\left(\mathrm{CDCl}_{3}, 75 \mathrm{MHz}, \delta, \mathrm{ppm}\right): 192.1,155.9,154.5,151.6,147.8$, $143.4,134.8,133.9,128.9,128.6,128.2,128.1,128.0,127.7,124.1$, 124.0, 117.3, 64.1, 50.7, 38.0, 34.7, 28.6, 28.3. IR (KBr, $\left.v, \mathrm{~cm}^{-1}\right)$ : 3078, 2972, 2958, 1647, 1521, 1311.

2.3. Reduction of Nitro Group (2). Compound 1 (1 mmol) and $\mathrm{SnCl}_{2} \cdot 2 \mathrm{H}_{2} \mathrm{O}(5 \mathrm{mmol})$ in THF-DMF $(4: 2 \mathrm{v} / \mathrm{v})$ were stirred at room temperature for $12 \mathrm{~h}$. After completion of the reaction, the solvent was evaporated under reduced pressure and the mixture was stirred with water, and extracted with chloroform. The organic phase was dried over $\mathrm{MgSO}_{4}$ and filtered and then purified by crystallisation from hexane.

2.3.1. 13-(4-Aminophenyl)-3,3-dimethyl-3,4-dihydro-2H-indazolo[1,2-b]phthalazine-1,6,11(13H)-trione (2). Yield 40\%, m.p. $263-265^{\circ} \mathrm{C}$; ${ }^{1} \mathrm{H}$ NMR $\left(\mathrm{CDCl}_{3}, 300 \mathrm{MHz}, \delta\right.$, ppm): 1.20 $(3 \mathrm{H}, \mathrm{s}), 1.22(3 \mathrm{H}, \mathrm{s}), 2.34(2 \mathrm{H}, \mathrm{s}), 3.18-3.44(2 \mathrm{H}, \mathrm{AB}$ system, $J: 19.21), 6.51(1 \mathrm{H}, \mathrm{s}), 6.59-6.62(2 \mathrm{H}, \mathrm{d}, J: 8.54), 7.17-7.20(2 \mathrm{H}$, d, J: 8.52), $7.26(2 \mathrm{H}, \mathrm{s}), 7.81-7.84(2 \mathrm{H}, \mathrm{m}), 8.25-8.28(1 \mathrm{H}, \mathrm{m})$, 8.31-8.34 (1H, m). ${ }^{13} \mathrm{C} \mathrm{NMR}$ (75 MHz, $\left.\mathrm{CDCl}_{3}, \delta, \mathrm{ppm}\right): 192.2$, $156.0,154.2,150.6,146.8,134.4,133.3,129.2,128.9,128.4,127.9$, $127.8,127.6,125.9,118.7,115.1,115.0,64.7,51.0,38.0,34.6,28.6$, 28.5. IR (KBr, $v, \mathrm{~cm}^{-1}$ ): 3477, 3367, 3028, 2953, 2958, 1651, 1517, 1357. Anal. Calcd. For $\mathrm{C}_{23} \mathrm{H}_{21} \mathrm{~N}_{3} \mathrm{O}_{3} \mathrm{~m} / z$ : 387.4; found $(\mathrm{M}+1): 388.0$.

2.4. General Procedure 3: Synthesis of 2H-Indazolo[2,1-b] phthalazine-trione Derivative Substituted Urea and Thiourea Derivatives (3a-3p). 13-(4-Aminophenyl)-3,3-dimethyl-3,4dihydro-2H-indazolo[1,2-b]phthalazine-1,6,11(13H)-trione

(2) (1,3 mmol), $\mathrm{Et}_{3} \mathrm{~N}$ (1,3 mmol), and isocyanate or isothiocyanate derivatives $(3 \mathrm{mmol})$ in THF $(20 \mathrm{~mL})$ were stirred at $60^{\circ} \mathrm{C}$ for 20 hours. After the reaction was completed, the precipitate was filtered under suction, washed with ether, and dried. 
2.4.1. 1-(4-(3,3-Dimethyl-1,6,11-trioxo-2,3,4,6,11,13-hexahydro$1 H$-indazolo[1,2-b]phthalazin-13-yl)phenyl)-3-phenylthiourea (3a). Yield $60 \%$, m.p. $362-364^{\circ} \mathrm{C} ;{ }^{1} \mathrm{H}$ NMR (DMSO- $\mathrm{d}_{6}$, $300 \mathrm{MHz}): 1.12(6 \mathrm{H}, \mathrm{s}), 2.20(2 \mathrm{H}, \mathrm{s}), 3.18-3.44(2 \mathrm{H}, \mathrm{AB}$ system, $J: 19.21), 6.20(1 \mathrm{H}, \mathrm{s}), 7.09-7.12(1 \mathrm{H}, \mathrm{m}), 7.20-7.34$ (2H, m), 7.30-7.47 (6H, m), 7.90-7.93 (2H, m), 8.05-8.08 (1H, $\mathrm{m}), 8.20-8.23(1 \mathrm{H}, \mathrm{m}), 9.60(1 \mathrm{H}, \mathrm{s}), 9.73(1 \mathrm{H}, \mathrm{s}) .{ }^{13} \mathrm{C} \mathrm{NMR}$ (DMSO-d 6 , $75 \mathrm{MHz}$ ): 192.6, 180.0, 156.0, 154.3, 151.9, 140.0, 139.9, 135.2, 134.3, 133.8, 129.6, 129.3, 129.2, 128.3, 128.2, 128.1, $127.4,125.0,124.2,124.1,124.0,123.6,117.9,117.8,79.8,64.6$, 50.9, 37.9, 34.9, 28.6. IR (KBr, $\left.v, \mathrm{~cm}^{-1}\right)$ : 3286, 3011, 2956, 1656, 1514, 1357. Anal. Calcd. For $\mathrm{C}_{30} \mathrm{H}_{26} \mathrm{~N}_{4} \mathrm{O}_{3} \mathrm{~S} m / z$ : 522.6; found $(\mathrm{M}+1): 523.1$.

2.4.2. 1-(4-(3,3-Dimethyl-1,6,11-trioxo-2,3,4,6,11,13-hexahydro-1H-indazolo[1,2-b]phthalazin-13-yl)phenyl)-3-(3-methoxyphenyl)thiourea (3b). Yield $70 \%$, m.p. $275-277^{\circ} \mathrm{C} ;{ }^{1} \mathrm{H}$ NMR (DMSO-d $\left.\mathrm{d}_{6}, 300 \mathrm{MHz}\right): 1.10(6 \mathrm{H}, \mathrm{s}), 2.24(2 \mathrm{H}, \mathrm{s})$, 3.18-3.44 (2H, AB system, J: 19.21), $3.69(3 \mathrm{H}, \mathrm{s}), 6.24(1 \mathrm{H}, \mathrm{s})$, 6.64-6.68 (1H, d, J: 7.98), 6.97-7.00 (1H, d, J: 7.95), 7.13-7.21 (2H, m), 7.37-7.42 (4H, m), 7.91-7.95 (2H, m), 8.05-8.08 (1H, m), 8.21-8.24 (1H, m), $9.76(1 \mathrm{H}, \mathrm{s}), 9.83(1 \mathrm{H}, \mathrm{s}) .{ }^{13} \mathrm{C} \mathrm{NMR}$ (DMSO-d 6 , $75 \mathrm{MHz}$ ): 192.6, 179.8, 159.9, 156.0, 154.3, 151.9, $141.1,139.9,135.2,134.4,133.9,129.9,129.7,129.3,128.2,127.4$, $123.7,117.9,116.2,116.0,110.3,109.6,79.8,64.6,55.7,50.9,37.9$, 36.4 34.9, 31.4, 28.6. IR (KBr, $\left.v, \mathrm{~cm}^{-1}\right)$ : 3273, 3015, 2956, 1651, 1514,1355 . Anal. Calcd. For $\mathrm{C}_{31} \mathrm{H}_{28} \mathrm{~N}_{4} \mathrm{O}_{4} \mathrm{~S} m / z$ : 552.6; found $(\mathrm{M}+1): 553.1$.

2.4.3. 1-(4-(3,3-Dimethyl-1,6,11-trioxo-2,3,4,6,11,13-hexahydro-1H-indazolo[1,2-b]phthalazin-13-yl)phenyl)-3-p-tolylthiourea (3c). Yield 82\%, m.p. $348-350{ }^{\circ} \mathrm{C} ;{ }^{1} \mathrm{H}$ NMR (DMSO- $\mathrm{d}_{6}$, $300 \mathrm{MHz}): 1.10(6 \mathrm{H}, \mathrm{s}), 2.24(3 \mathrm{H}, \mathrm{s}), 2.28(2 \mathrm{H}, \mathrm{s}), 3.18-3.44$ $(2 \mathrm{H}, \mathrm{AB}$ system, J: 19.21), $6.24(1 \mathrm{H}, \mathrm{s}), 7.08-7.11(2 \mathrm{H}, \mathrm{d}$;: 8.10), 7.21-7.31 (4H, m), 7.37-7.39 (2H, d, J: 7.97), 7.92-7.95 $(2 \mathrm{H}, \mathrm{m}), 8.06-8.09(1 \mathrm{H}, \mathrm{m}), 8.22-8.25(1 \mathrm{H}, \mathrm{m}), 9.67(1 \mathrm{H}$, s), $9.74(1 \mathrm{H}, \mathrm{s}) .{ }^{13} \mathrm{C} \mathrm{NMR}\left(\mathrm{DMSO}-\mathrm{d}_{6}, 75 \mathrm{MHz}\right): 192.7,179.9$, $156.0,154.3,151.9,140.0,138.5,137.5,137.3,135.2,134.3,134.2$, $133.7,131.0,129.7,129.6,129.3,128.2,127.4,126.4,124.5,124.4$, 123.6, 117.9, 79.8, 64.6, 50.9, 37.9, 34.9, 28.7, 28.6. IR (KBr, $v$, $\left.\mathrm{cm}^{-1}\right): 3277,3030,2956,1656,1510,1357$. Anal. Calcd. For $\mathrm{C}_{31} \mathrm{H}_{28} \mathrm{~N}_{4} \mathrm{O}_{3} \mathrm{~S} m / z$ : 536.6; found $(\mathrm{M}+1)$ : 537.1 .

2.4.4. 1-(4-(3,3-Dimethyl-1,6,11-trioxo-2,3,4,6,11,13-hexahydro-1H-indazolo[1,2-b]phthalazin-13-yl)phenyl)-3-(4-chlorophenyl)thiourea (3d). Yield 80\%, m.p. $382-384^{\circ} \mathrm{C} ;{ }^{1} \mathrm{H}$ NMR (DMSO-d $6,300 \mathrm{MHz}): 1.12(6 \mathrm{H}, \mathrm{s}), 2.27(2 \mathrm{H}, \mathrm{s}), 3.18-3.44$ $(2 \mathrm{H}, \mathrm{AB}$ system, J: 19.21), 6.27 (1H, s), 7.35-7.38 (2H, d, J: 8.75), 7.40 (4H, s), 7.47-7.50 (2H, d, J: 8.78), 7.95-7.98 (2H, m), 8.09-8.12 (1H, m), 8.24-8.28 (1H, m), $9.89(1 \mathrm{H}, \mathrm{s}), 9.94(1 \mathrm{H}$, s). ${ }^{13} \mathrm{C}$ NMR (DMSO-d 6 , $75 \mathrm{MHz}$ ): 192.7, 180.0, 156.0, 154.4, 152.0, 139.7, 139.1, 135.2, 134.4, 134.0, 129.7, 129.3, 129.2, 129.0, $128.8,128.3,128.2,127.4,125.8,123.7,117.9,80.0,67.7,64.6,50.9$, 37.9, 34.9, 28.7, 28.6, 25.8.IR ( $\left.\mathrm{KBr}, v, \mathrm{~cm}^{-1}\right)$ : 3288, 3045, 2958, 1653, 1512, 1357. Anal. Calcd. For $\mathrm{C}_{30} \mathrm{H}_{25} \mathrm{ClN}_{4} \mathrm{O}_{3} \mathrm{~S} m / z$ : 557.0; found $(\mathrm{M}+1): 558.5$.
2.4.5. 1-(4-(3,3-Dimethyl-1,6,11-trioxo-2,3,4,6,11,13-hexahydro-1H-indazolo[1,2-b]phthalazin-13-yl)phenyl)-3-(4-iodophenyl)thiourea (3e). Yield $84 \%$, m.p. $395-397^{\circ} \mathrm{C} ;{ }^{1} \mathrm{H}$ NMR (DMSO-d, $300 \mathrm{MHz}): 1.09$ (6H, s), $2.24(2 \mathrm{H}, \mathrm{s}), 3.18-3.44$ (2H, AB system, J: 19.21), $6.24(1 \mathrm{H}, \mathrm{s}), 7.29-7.26(2 \mathrm{H}, \mathrm{d}, J$ : 7.30), 7.37 (4H, s), 7.60-7.63 (2H, d, J: 7.18), 7.92-7.96 (2H, m), 8.06-8.09 (1H, m), 8.22-8.25 (1H, m), $9.84(1 \mathrm{H}, \mathrm{s}), 9.88(1 \mathrm{H}$, s). ${ }^{13} \mathrm{C}$ NMR (DMSO-d $\left.6,75 \mathrm{MHz}\right): 192.7,179.9,156.0,154.4$, 152.0, 140.0, 139.9, 139.7, 137.7, 135.2, 134.4, 134.0, 129.7, 129.3, $128.3,128.2,127.4,126.4,126.2,126.0,123.7,117.9,89.2,64.6$, 50.9, 37.9, 34.9, 32.6, 28.7, 28.6. IR $\left(\mathrm{KBr}, v, \mathrm{~cm}^{-1}\right)$ : 3259, 3037, 2953, 1647, 1529, 1359. Anal. Calcd. For $\mathrm{C}_{30} \mathrm{H}_{25} \mathrm{IN}_{4} \mathrm{O}_{3} \mathrm{~S} m / z$ : 648.5; found $(M+1): 649.0$.

2.4.6. 1-(4-(3,3-Dimethyl-1,6,11-trioxo-2,3,4,6,11,13-hexahydro-1H-indazolo[1,2-b]phthalazin-13-yl)phenyl)-3-(4-bromophenyl)thiourea (3f). Yield 80\%, m.p. $373-375^{\circ} \mathrm{C} ;{ }^{1} \mathrm{H}$ NMR (DMSO-d $6,300 \mathrm{MHz}): 1.09(6 \mathrm{H}, \mathrm{s}), 2.24(2 \mathrm{H}, \mathrm{s}), 3.18-3.44$ (2H, AB system, J: 19.21), $6.24(1 \mathrm{H}, \mathrm{s}), 7.38(4 \mathrm{H}, \mathrm{s}), 7.39-7.48$ $(4 \mathrm{H}, \mathrm{m}), 7.92-7.95(2 \mathrm{H}, \mathrm{m}), 8.06-8.09(1 \mathrm{H}, \mathrm{m}), 8.22-8.25(1 \mathrm{H}$, m), $9.86(1 \mathrm{H}, \mathrm{s}), 9.91(1 \mathrm{H}, \mathrm{s}) .{ }^{13} \mathrm{C}$ NMR (DMSO-d $\left.6,75 \mathrm{MHz}\right)$ : $192.7,180.0,156.0,154.4,151.9,151.6,139.7,139.5,134.0,132.5$, $132.0,131.9,129.7,129.3,128.3,127.4,126.0,125.9,123.7,118.6$, $117.9,117.8,117.0,79.8,64.6,50.9,37.9,34.9,28.7,28.6$. IR (KBr, $\left.v, \mathrm{~cm}^{-1}\right): 3265,3060,2951,1651,1537,1358$. Anal. Calcd. For $\mathrm{C}_{30} \mathrm{H}_{25} \mathrm{BrN}_{4} \mathrm{O}_{3} \mathrm{~S} m / z$ : 601.5 ; found $(\mathrm{M}+1)$ : 602.9.

2.4.7. 1-(4-(3,3-Dimethyl-1,6,11-trioxo-2,3,4,6,11,13-hexahydro$1 H$-indazolo[1,2-b]phthalazin-13-yl)phenyl)-3-(4-florophenyl) thiourea (3g). Yield 68\%, m.p. $220-222^{\circ} \mathrm{C} ;{ }^{1} \mathrm{H}$ NMR (DMSO-d $\left.\mathrm{D}_{6}, 300 \mathrm{MHz}\right): 1.09(6 \mathrm{H}, \mathrm{s}), 2.24(2 \mathrm{H}, \mathrm{s}), 3.18-3.44$ (2H, AB system, J: 19.21), $6.24(1 \mathrm{H}, \mathrm{s}), 7.09-7.15$ (2H, t, J: 8.90), 7.37-7.39 (4H, m), 7.41-7.44 (2H, t, J: 7.19), 7.91-7.95 (2H, m), 8.06-8.09 (1H, m), 8.21-8.24 (1H, m), $8.29(1 \mathrm{H}, \mathrm{s}), 8.30(1 \mathrm{H}$, s). ${ }^{13} \mathrm{C} \mathrm{NMR}$ (DMSO-d 6 , $75 \mathrm{MHz}$ ): 192.6, 180.4, 161.3, 156.0, $154.4,151.9,139.8,136.3,136.2,135.2,134.4,133.9,129.7,129.3$, $128.3,128.2,127.4,126.9,126.8,123.7,117.9,115.8,115.5,79.8$, 64.6, 50.9, 37.9, 34.9, 28.7, 28.6. IR (KBr, $\left.v, \mathrm{~cm}^{-1}\right)$ : 3278, 3067, 2958, 1654, 1504, 1357. Anal. Calcd. For $\mathrm{C}_{30} \mathrm{H}_{25} \mathrm{FN}_{4} \mathrm{O}_{3} \mathrm{~S} m / z$ : 540.6; found $(\mathrm{M}+1): 540.9$.

2.4.8. 1-(4-(3,3-Dimethyl-1,6,11-trioxo-2,3,4,6,11,13-hexahydro-1H-indazolo[1,2-b]phthalazin-13-yl)phenyl)-3-phenylurea (3h). Yield 56\%, m.p. $370-372^{\circ} \mathrm{C} ;{ }^{1} \mathrm{H}$ NMR (DMSO- $\mathrm{d}_{6}$, $300 \mathrm{MHz}): 1.20(3 \mathrm{H}, \mathrm{s}), 1.21(3 \mathrm{H}, \mathrm{s}), 2.33(2 \mathrm{H}, \mathrm{s}), 3.18-3.44$ $(2 \mathrm{H}, \mathrm{AB}$ system, $J: 19.21), 6.36(1 \mathrm{H}, \mathrm{s}), 6.93-6.99(1 \mathrm{H}, \mathrm{m})$, 7.03-7.06 (2H, d, J: 8.95), 7.20-7.26 (4H, m), 7.31-7.34 (2H, d, J: 9.13), 7.50 (1H, s), 7.86-7.89 (2H, m), $7.94(1 \mathrm{H}, \mathrm{s}), 8.23-8.26$ $(1 \mathrm{H}, \mathrm{m}), 8.37-8.40(1 \mathrm{H}, \mathrm{m}) .{ }^{13} \mathrm{C}$ NMR (DMSO-d $\left.6,75 \mathrm{MHz}\right)$ : 192.6, 156.0, 154.3, 153.1, 151.7, 140.3, 140.2, 140.1, 135.2, 134.3, $134.2,131.4,129.7,129.4,128.6,128.2,127.4,122.5,120.2$, 119.5, $118.8,118.7,118.6,118.1,104.1,64.7,51.0,37.9,34.9,28.7$. IR $\left(\mathrm{KBr}, v, \mathrm{~cm}^{-1}\right): 3477,3365,3037,2953,1645,1538,1307$. Anal. Calcd. For $\mathrm{C}_{30} \mathrm{H}_{26} \mathrm{~N}_{4} \mathrm{O}_{4} \mathrm{~m} / z$ : 506.5; found $(\mathrm{M}+1)$ : 507.3 . 
2.4.9. 1-(4-(3,3-Dimethyl-1,6,11-trioxo-2,3,4,6,11,13-hexahydro-1H-indazolo[1,2-b]phthalazin-13-yl)phenyl)-3-(4-nitrophenyl)urea (3i). Yield $70 \%$, m.p. $383-385^{\circ} \mathrm{C} ;{ }^{1} \mathrm{H}$ NMR (DMSO-d 6 , $300 \mathrm{MHz}): 1.09(3 \mathrm{H}, \mathrm{s}), 1.10(3 \mathrm{H}, \mathrm{s}), 2.23(2 \mathrm{H}, \mathrm{s})$, 3.18-3.44 (2H, AB system, J: 19.21), 6.25 (1H, s), 7.35-7.36 $(4 \mathrm{H}, \mathrm{s}), 7.62-7.66$ (2H, d, J: 9.35), 7.91-7.94 (2H, m), 8.04-8.08 $(1 \mathrm{H}, \mathrm{m}), 8.13-8.16(2 \mathrm{H}, \mathrm{d}, J: 9.32), 8.21-8.24(1 \mathrm{H}, \mathrm{m}), 8.92$ $(1 \mathrm{H}, \mathrm{s}), 9.41(1 \mathrm{H}, \mathrm{s}) .{ }^{13} \mathrm{C}$ NMR (DMSO-d $\left.6,75 \mathrm{MHz}\right): 192.6$, 156.0, 154.3, 152.5, 152.3, 151.7, 147.0, 146.3, 142.1, 141.6, 139.3, 132.1, 129.7, 129.3, 128.7, 128.6, 125.8, 125.7, 119.1, 118.6, 118.1, $118.0,80.0,64.6,38.9,37.9,34.9,28.7,28.5,25.8$. IR (KBr, $v$, $\left.\mathrm{cm}^{-1}\right): 3369,3099,2956,1664,1598,1301$. Anal. Calcd. For $\mathrm{C}_{30} \mathrm{H}_{25} \mathrm{~N}_{5} \mathrm{O}_{6} m / z$ : 551.4; found $(\mathrm{M}+1)$ : 552.5 .

2.4.10. 1-(4-(3,3-Dimethyl-1,6,11-trioxo-2,3,4,6,11,13-hexahydro-1H-indazolo[1,2-b]phthalazin-13-yl)phenyl)-3-(3-methoxyphenyl)urea (3j). Yield 70\%, m.p. $330-332^{\circ} \mathrm{C} ;{ }^{1} \mathrm{H}$ NMR (DMSO-d $6,300 \mathrm{MHz}): 1.10(6 \mathrm{H}, \mathrm{s}), 2.24(2 \mathrm{H}, \mathrm{s}), 3.18-3.44$ (2H, AB system, J: 19.21), 3.68-3.70 (3H, s), $6.20(1 \mathrm{H}, \mathrm{s})$, 6.49-6.54 (2H, m), 6.87-6.91 (2H, m), 7.13-7.14 (2H, m), 7.32 $(2 \mathrm{H}, \mathrm{s}), 7.91-7.96(2 \mathrm{H}, \mathrm{m}), 8.06-8.11(1 \mathrm{H}, \mathrm{m}), 8.22-8.27(1 \mathrm{H}$, m), $8.63(1 \mathrm{H}, \mathrm{s}), 8.64(1 \mathrm{H}, \mathrm{s}) .{ }^{13} \mathrm{C}$ NMR (DMSO-d $\left.6,75 \mathrm{MHz}\right)$ : $192.6,179.8,159.9,156.0,154.3,151.9,141.1,139.9,135.2,134.4$, $133.9,129.9,129.7,129.3,128.2,127.4,123.7,117.9,116.2,116.0$, $110.3,109.6,79.8,64.6,55.7,50.9,37.9,36.4,34.9,31.4,28.6$. IR $\left(\mathrm{KBr}, v, \mathrm{~cm}^{-1}\right): 3360,3067,1664,1539,1355$. Anal. Calcd. For $\mathrm{C}_{31} \mathrm{H}_{28} \mathrm{~N}_{4} \mathrm{O}_{5} \mathrm{~m} / z$ : 536.5; found $(\mathrm{M}+1)$ : 536.9 .

2.4.11. 1-(4-(3,3-Dimethyl-1,6,11-trioxo-2,3,4,6,11,13-hexahydro-1H-indazolo[1,2-b]phthalazin-13-yl)phenyl)-3-p-tolylurea (3k). Yield 66\%, m.p. $397-399^{\circ} \mathrm{C} ;{ }^{1} \mathrm{H}$ NMR (DMSO-d ${ }_{6}$, $300 \mathrm{MHz}): 1.10(6 \mathrm{H}, \mathrm{s}) ; 2.20(3 \mathrm{H}, \mathrm{s}), 2.24(2 \mathrm{H}, \mathrm{s}), 3.18-3.44$ $(2 \mathrm{H}, \mathrm{AB}$ system, $J: 19.21), 6.20(1 \mathrm{H}, \mathrm{s}), 7.02-7.05(2 \mathrm{H}, \mathrm{m})$, 7.27-7.32 (4H, m), 7.91-7.94 (2H, m), 8.04-8.08 (1H, m), 8.21-8.25 (1H, m), 8.28-8.29 (2H, m), $8.50(1 \mathrm{H}, \mathrm{s}), 8.60$ (1H, s). ${ }^{13} \mathrm{C}$ NMR (DMSO-d 6 , $75 \mathrm{MHz}$ ): 192.6, 156.1, 156.0, $154.3,153.1,151.7,140.2,137.7,135.2,134.3,131.2,129.8,129.7$, $129.4,128.6,128.2,127.4,118.9,118.6,118.1,80.0,79.8,79.6$, $79.2,64.7,50.9,37.9,34.9,28.7,28.5,21.0$. IR $\left(\mathrm{KBr}, v, \mathrm{~cm}^{-1}\right)$ : 3383, 3298, 3082, 2953, 1666, 1510, 1309. Anal. Calcd. For $\mathrm{C}_{31} \mathrm{H}_{28} \mathrm{~N}_{4} \mathrm{O}_{4} \mathrm{~m} / z$ : 520.5; found $(\mathrm{M}+1)$ : 521.3 .

2.4.12. 1-(4-(3,3-Dimethyl-1,6,11-trioxo-2,3,4,6,11,13-hexahydro-1H-indazolo[1,2-b]phthalazin-13-yl)phenyl)-3-(4-florophenyl)urea (3l). Yield 64\%, m.p. $375-377^{\circ} \mathrm{C} ;{ }^{1} \mathrm{H}$ NMR (DMSO-d $6,300 \mathrm{MHz}): 1.21(6 \mathrm{H}, \mathrm{s}), 2.31(2 \mathrm{H}, \mathrm{s}), 3.18-3.44$ $(2 \mathrm{H}, \mathrm{AB}$ system, J: 19.21), $6.33(1 \mathrm{H}, \mathrm{s}), 6.93-6.98(2 \mathrm{H}, \mathrm{m})$, 7.29-7.32 (2H, t, J: 1.76), 7.34-7.37 (2H, m), 7.39-7.42 (2H, t, J: 1.08), 7.87-7.90 (2H, m), 8.17-8.20 (1H, m), 8.30-8.33 (1H, m), $8.38(1 \mathrm{H}, \mathrm{m}), 8.42(1 \mathrm{H}, \mathrm{s}) .{ }^{13} \mathrm{C}$ NMR $\left(\mathrm{DMSO}_{-} \mathrm{d}_{6}, 75 \mathrm{MHz}\right)$ : 192.6, 156.4, 156.0, 154.3, 153.2, 151.7, 140.1, 136.6, 135.1, 134.3, $131.4,129.6,129.4,128.6,128.1,127.5,127.4,120.6,120.5,118.7$, $118.6,118.1,116.0,115.8,64.7,50.9,37.9,34.9,28.7,28.5$. IR $\left(\mathrm{KBr}, v, \mathrm{~cm}^{-1}\right): 3367,3313,3075,1664,1504,1307$. Anal. Calcd. For $\mathrm{C}_{30} \mathrm{H}_{25} \mathrm{FN}_{4} \mathrm{O}_{4} \mathrm{~m} / z$ : 524.5 ; found $(\mathrm{M}+1)$ : 525.6.

2.4.13. 1-(4-(3,3-Dimethyl-1,6,11-trioxo-2,3,4,6,11,13-hexahydro-1H-indazolo[1,2-b]phthalazin-13-yl)phenyl)-3-hexylurea (3m). Yield 60\%, m.p. 265-267 ${ }^{\circ}$; ${ }^{1} \mathrm{H}$ NMR (DMSO- $\mathrm{d}_{6}$, $300 \mathrm{MHz}): 0.80-0.84(3 \mathrm{H}, \mathrm{t}, J: 6.26), 1.09(6 \mathrm{H}, \mathrm{s}), 1.22(6 \mathrm{H}$, s), $1.32-1.38(2 \mathrm{H}, \mathrm{m}), 2.23(2 \mathrm{H}, \mathrm{s}), 2.98-3.02(2 \mathrm{H}, \mathrm{t}, J: 6.06)$, 3.18-3.44 (2H, AB system, J: 19.21), 6.04-6.08 (1H, t, J: 5.58), $6.17(1 \mathrm{H}, \mathrm{s}), 7.24(4 \mathrm{H}, \mathrm{s}), 7.91-7.94(2 \mathrm{H}, \mathrm{m}), 8.05-8.08(1 \mathrm{H}$, $\mathrm{m}), 8.21-8.24(1 \mathrm{H}, \mathrm{m}), 8.38(1 \mathrm{H}, \mathrm{s}) .{ }^{13} \mathrm{C} \mathrm{NMR}\left(\mathrm{DMSO}_{6} \mathrm{~d}_{6}\right.$, $75 \mathrm{MHz}$ ): 192.6, 156.0, 154.2, 151.7, 141.0, 135.2, 134.3, 130.3, $129.6,129.4,128.5,128.1,127.3,118.1,117.9,80.0,79.6,79.1,64.7$, 50.9, 37.9, 34.9, 31.7, 31.3, 30.3, 28.7, 28.5, 26.7, 22.7, 14.6. IR $\left(\mathrm{KBr}, v, \mathrm{~cm}^{-1}\right): 3402,3354,3040,2960,1662,1541,1352$. Anal. Calcd. For $\mathrm{C}_{30} \mathrm{H}_{34} \mathrm{~N}_{4} \mathrm{O}_{4} \mathrm{~m} / z$ : 514.6; found $(\mathrm{M}+1)$ : 515.5 .

2.4.14. 1-(4-(3,3-Dimethyl-1,6,11-trioxo-2,3,4,6,11,13-hexahydro-1H-indazolo[1,2-b]phthalazin-13-yl)phenyl)-3-propylurea (3n). Yield 74\%, m.p. $353-355^{\circ} \mathrm{C}$; ${ }^{1} \mathrm{H}$ NMR (DMSO- $\mathrm{d}_{6}$, $300 \mathrm{MHz}$ ): $0.82-0.84$ (3H, t, J: 6.26), 1.08 (6H, s), 1.32-1.39 $(2 \mathrm{H}, \mathrm{s}), 2.23(2 \mathrm{H}, \mathrm{s}), 2.98-3.02(2 \mathrm{H}, \mathrm{t}), 3.18-3.44(2 \mathrm{H}, \mathrm{AB}$ system, J: 19.21), 6.04-6.07 (1H, t, J: 5.58), $6.12(1 \mathrm{H}, \mathrm{s}), 7.22$ (4H, s), 7.90-7.93 (2H, m), 8.05-8.09 (1H, m), 8.20-8.23 (1H, $\mathrm{m}), 8.37(1 \mathrm{H}, \mathrm{s}) .{ }^{13} \mathrm{C}$ NMR (DMSO-d 6 , $\left.75 \mathrm{MHz}\right)$ : 192.6, 156.0, 154.2, 151.7, 141.0, 135.2, 134.3, 130.3, 129.6, 129.4, 128.5, 128.1, 127.3, 118.1, 117.9, 79.6, 79.1, 64.7, 50.9, 37.9, 34.9, 31.3, 28.7, 28.5, 26.7, 22.7, 14.6. IR (KBr, $\left.v, \mathrm{~cm}^{-1}\right): 3394,3354,3042,2958$, 2932, 1649, 1537, 1354. Anal. Calcd. For $\mathrm{C}_{27} \mathrm{H}_{28} \mathrm{~N}_{4} \mathrm{O}_{4} \mathrm{~m} / z$ : 486.5; found $(\mathrm{M}+1)$ : 487.2.

2.4.15. 1-(4-(3,3-Dimethyl-1,6,11-trioxo-2,3,4,6,11,13-hexahydro-1H-indazolo[1,2-b]phthalazin-13-yl)phenyl)-3-isopropylurea (3o). Yield 50\%, m.p. 218-219 ${ }^{\circ}$; ${ }^{1} \mathrm{H}$ NMR (DMSO- $\mathrm{d}_{6}$, $300 \mathrm{MHz}): 0.82-0.87$ (3H, t, J: 6.26), 1.08 (6H, s), $1.22-1.39$ $(3 \mathrm{H}, \mathrm{s}), 2.20(2 \mathrm{H}, \mathrm{s}), 2.98-3.04(1 \mathrm{H}, \mathrm{t}, \mathrm{J}: 6.06), 3.18-3.44(2 \mathrm{H}$, AB system, J: 19.21), 6.02-6.06 (1H, t, J: 5.58), $6.11(1 \mathrm{H}, \mathrm{s}), 7.25$ $(4 \mathrm{H}, \mathrm{s}), 7.90-7.93(2 \mathrm{H}, \mathrm{m}), 8.09-8.10(1 \mathrm{H}, \mathrm{m}), 8.19-8.21(1 \mathrm{H}$, m), $8.39(1 \mathrm{H}, \mathrm{s}) .{ }^{13} \mathrm{C}$ NMR (DMSO-d 6 , $\left.75 \mathrm{MHz}\right):$ 192.6, 156.0, 154.2 , 151.7, 141.0, 135.2, 134.3, 130.3, 129.6, 129.4, 128.5, 128.1, $127.3,118.1,117.9,79.6,79.1,64.7,50.9,37.9,34.9,31.3,28.7,28.5$, 26.7, 22.7, 14.6. IR (KBr, $\left.v, \mathrm{~cm}^{-1}\right): 3392,3354,3045,2958$, 2932, 1649, 1537, 1355. Anal. Calcd. For $\mathrm{C}_{27} \mathrm{H}_{28} \mathrm{~N}_{4} \mathrm{O}_{4} \mathrm{~m} / z$ : 472.5; found $(M+1)$ : 473.7.

2.4.16. 1-(4-(3,3-Dimethyl-1,6,11-trioxo-2,3,4,6,11,13-hexahydro-1H-indazolo[1,2-b]phthalazin-13-yl)phenyl)-3-ethylurea (3p). Yield $48 \%$, m.p. $360-362^{\circ} \mathrm{C} ;{ }^{1} \mathrm{H}$ NMR (DMSO- $\mathrm{d}_{6}$, $300 \mathrm{MHz}$ ): 0.81-0.86 (3H, t, J: 6.26), 1.07 (6H, s), $2.19(2 \mathrm{H}, \mathrm{s})$, 2.97-3.04 (2H, t, J: 6.06), 3.18-3.44 (2H, AB system, J: 19.21), 6.02-6.06 (1H, t, J: 5.58), $6.12(1 \mathrm{H}, \mathrm{s}), 7.23(4 \mathrm{H}, \mathrm{s}), 7.90-7.93$ $(2 \mathrm{H}, \mathrm{m}), 8.09-8.10(1 \mathrm{H}, \mathrm{m}), 8.19-8.21(1 \mathrm{H}, \mathrm{m}), 8.39(1 \mathrm{H}, \mathrm{s})$. ${ }^{13} \mathrm{C}$ NMR (DMSO-d $6,75 \mathrm{MHz}$ ): 192.6, 156.0, 155.7, 154.2, 151.7, 141.0, 135.2, 134.3, 130.4, 129.7, 129.5, 129.4, 128.5, 128.1, 127.4, 118.2, 118.1, 118.0, 64.7, 50.9, 37.9, 34.9, 34.5, 28.7, 28.5, 16.1. IR ( $\left.\mathrm{KBr}, v, \mathrm{~cm}^{-1}\right): 3406,3367,3045,2976,2960,1651$, 1533, 1355. Anal. Calcd. For $\mathrm{C}_{26} \mathrm{H}_{26} \mathrm{~N}_{4} \mathrm{O}_{4} \mathrm{~m} / z$ : 458.5; found $(\mathrm{M}+1): 459.0$.

2.5. CA Enzyme Assay. Blood samples $(25 \mathrm{~mL})$ were taken from healthy human volunteers. They were anticoagulated with acid-citrate-dextrose and centrifuged at $2000 \mathrm{~g}$ for $20 \mathrm{~min}$ at $4^{\circ} \mathrm{C}$, and the supernatant was removed. The packed 
erythrocytes were washed three times with $0.9 \% \mathrm{NaCl}$ and then haemolysed in cold water. The ghosts and any intact cells were removed by centrifugation at $2000 \mathrm{~g}$ for $25 \mathrm{~min}$ at $4^{\circ} \mathrm{C}$, and the $\mathrm{pH}$ of the haemolysate was adjusted to $\mathrm{pH}$ 8.5 with solid tris-base. The $25 \mathrm{~mL}$ haemolysate was applied to an affinity column containing L-tyrosine-sulfonamideSepharose-4B [32] equilibrated with $25 \mathrm{mM}$ tris- $\mathrm{HCl} / 0.1 \mathrm{M}$ $\mathrm{Na}_{2} \mathrm{SO}_{4}$ (pH 8.5). The affinity gel was washed with $50 \mathrm{~mL}$ of $25 \mathrm{mM}$ tris- $\mathrm{HCl} / 22 \mathrm{mM} \mathrm{Na}_{2} \mathrm{SO}_{4}$ ( $\mathrm{pH}$ 8.5). The human CA (hCA) isozymes were then eluted with $0.1 \mathrm{M} \mathrm{NaCl} / 25 \mathrm{mM}$ $\mathrm{Na}_{2} \mathrm{HPO}_{4}\left(\mathrm{pH}\right.$ 6.3) and $0.1 \mathrm{M} \mathrm{CH}_{3} \mathrm{COONa} / 0.5 \mathrm{M} \mathrm{NaClO}_{4}$ (pH 5.6), which recovered hCA I and hCA II, respectively. Fractions of $3 \mathrm{~mL}$ were collected, and their absorbance was measured at $280 \mathrm{~nm}$. CA activity was measured by the Maren method which is based on determination of the time required for the $\mathrm{pH}$ to decrease from 10.0 to 7.4 due to $\mathrm{CO}_{2}$ hydration [33]. $\mathrm{CO}_{2}$-hydratase activity (enzyme units (EU)) was calculated by using the equation $t_{0}-t_{c} / t_{c}$ where $t_{0}$ and $t_{c}$ are the times for $\mathrm{pH}$ change of the nonenzymatic and the enzymatic reactions, respectively.

2.6. In Vitro Inhibition Studies. For the in vitro inhibition studies of urea and thiourea derivatives, different concentrations of these compounds were added to the enzyme. Activity percentage values of CA for different concentrations of each compound were determined by regression analysis using Microsoft Office 2000 Excel. CA enzyme activity without a synthesized compounds solution was accepted as $100 \%$ activity.

\section{Results and Discussion}

For evaluation of the physiologically relevant human CA isozymes (hCAs I and II) inhibitory activity, several new urea and thiourea compounds were subjected to CA inhibition assay with $\mathrm{CO}_{2}$ as a substrate. The results showed that phthalazine substituted urea and thiourea derivatives $(3 \mathbf{a}-\mathbf{p})$ inhibited the CA enzyme activity. The inhibition constants of the synthesized compounds against CAs were given in Table 1. We have determined the $\mathrm{IC}_{50}$ values of $6.40-20.38 \mu \mathrm{M}$ and $6.13-23.63 \mu \mathrm{M}$ for hCA I and hCA II, respectively, and they are all competitive inhibitors.

2H-Indazolo[2,1-b]phthalazine-trione compound (1) was prepared with 4-nitrobenzaldehyde, dimedone, and phthalhydrazide in the presence of TFA in DMF [34]. The nitro containing phthalhydrazide was reduced with tin (II) chloride in ethanol [35]. The amino phthalhydrazide was reacted with isocyanates or thioisocyanates to get the final products $(3 \mathbf{a}-\mathbf{p})$ (Scheme 2) at moderate yields [36].

All new compounds were characterized by ${ }^{1} \mathrm{H} \mathrm{NMR},{ }^{13} \mathrm{C}$ NMR, IR, and MS. In the infrared spectra of compounds $(3 \mathbf{a}-\mathbf{p})$, it was possible to observe the absorptions between 3250 and $3410 \mathrm{~cm}^{-1}$ relating to $\mathrm{NH}$ stretch and absorptions in $1645-1670 \mathrm{~cm}^{-1}$ from urea carbonyl moiety stretching. The ${ }^{1} \mathrm{H}$ NMR spectra for all the synthesized urea and thiourea compounds show signals as singlet between 6.10 and $10.00 \mathrm{ppm}$ relating to hydrogens attached to the nitrogen. The signals for aromatic hydrogens are between 6.50 and
TABLE 1: $\mathrm{IC}_{50}(\mu \mathrm{M})$ values of the phthalazine substituted urea and thiourea derivatives.

\begin{tabular}{lccccc}
\hline & hCA I & hCA II & & hCA I & hCA II \\
\hline $\mathbf{1}$ & 12,08 & 11,89 & $\mathbf{3 h}$ & 14,04 & 17,78 \\
$\mathbf{2}$ & 10,18 & 10,25 & $\mathbf{3 i}$ & 6,76 & 6,75 \\
$\mathbf{3 a}$ & 6,40 & 6,13 & $\mathbf{3 j}$ & 20,38 & 22,73 \\
$\mathbf{3 b}$ & 13,97 & 15,35 & $\mathbf{3 k}$ & 16,38 & 16,34 \\
3c & 18,20 & 23,63 & $\mathbf{3 1}$ & 12,62 & 12,34 \\
$\mathbf{3 d}$ & 19,59 & 18,21 & $\mathbf{3 m}$ & 7,63 & 9,67 \\
$\mathbf{3 e}$ & 11,02 & 8,50 & $\mathbf{3 n}$ & 8,20 & 8,74 \\
$\mathbf{3 f}$ & 12,20 & 19,12 & $\mathbf{3 o}$ & 7,45 & 10,03 \\
$\mathbf{3 g}$ & 8,72 & 8,25 & $\mathbf{3 p}$ & 11,72 & 10,04 \\
\hline
\end{tabular}

$8.50 \mathrm{ppm}$. The signals around $3.18 \mathrm{ppm}$ are seen as $\mathrm{AB}$ system with the coupling constant $19.21 \mathrm{~Hz}$. which is the germinalgerminal interaction. Through the ${ }^{13} \mathrm{C}$ NMR data, a sign can be seen about 150.0-160.0 ppm for urea carbonyl and 175.0180.0 ppm for thiourea carbonyl.

CA inhibitors decrease intraocular pressure by reducing bicarbonate formation in the ciliary process, so lowering $\mathrm{Na}^{+}$transport and flow of aqueous humour: this is the basis for their use in glaucoma treatment. Unfortunately, systemic therapy with parenteral sulphonamides leads to significant side effects, many of them being probably due to inhibition of CA isoforms in other tissues. Acetazolamide which is 20 times less active against hCA I than against hCA II in erythrocytes is the most widely used inhibitor. But the inhibition of various $\mathrm{CA}$ isoforms which are present in tissues other than eye leads to an entire range of side effects, the most prominent being numbness and tingling of extremities, metallic taste, depression, fatigue, malaise, weight loss, decreased libido, gastrointestinal irritation, metabolic acidosis, renal calculi, and transient myopia [7, 36, 37].

Sulfonamide compounds are coordinated to the zinc (II) ion within the hCAs active site, whereas its organic scaffold fills the entire enzyme cavity, making an extensive series of van der Waals and polar interactions with amino acid residues both at the bottom, middle, and entrance of the active site cavity [38]. Coumarins derivatives may possess various tautomeric forms which may bind within the CA active site similarly to phenols, that is, by anchoring to the zinc-bound water molecule/hydroxide ion [39]. Coumarins cannot bind enzyme effectively in the restricted space near $\mathrm{Zn}^{2+}$ ion because they have bulky group and exhibit unusual binding mode not interacting with the metal ion of the enzyme [40]. We assume that the synthesized compounds are very big pendant group to be able to bind near the zinc ion. Hence, they much more probably bind as the coumarin derivatives.

The results showed that all the compounds $(3 \mathbf{a}-\mathbf{p})$ inhibited the enzyme activity. The inhibition constants of the synthesized compounds against CAs were given in Table 1. The following structure-activity relationship (SAR) observations can be drawn from the data. The slow cytosolic isoform hCA I and the second off-target isoform hCA II were inhibited by the synthesized compounds with inhibition values in the 
<smiles>CC1(C)CC(=O)CC(C)(C)C1</smiles><smiles>[R]NC(=[X])Nc1ccc(C2NC(=O)c3ccccc3C2=O)cc1</smiles>

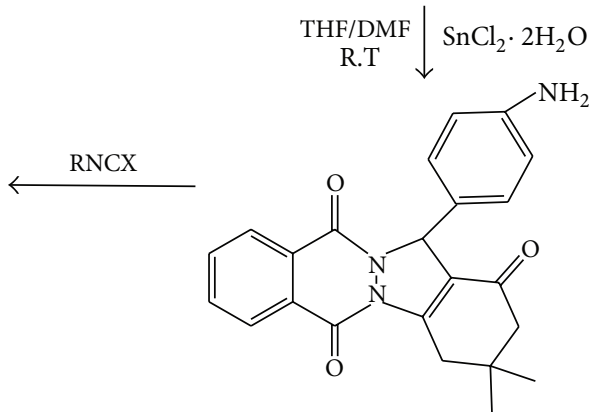

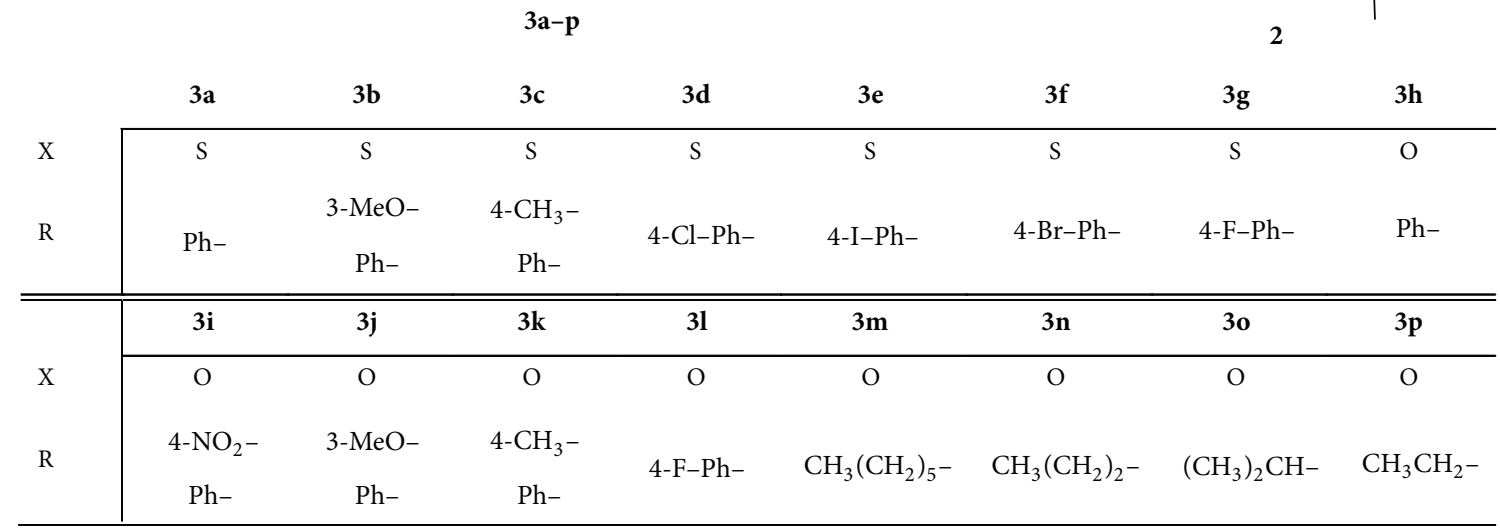

Scheme 2: Synthesis of phthalazine substituted urea and thiourea derivatives.

range of 6.00-24.00 $\mu \mathrm{M}$. The best hCA I and hCA II inhibitors among the newly synthesized and investigated compounds were $3 \mathbf{a}$ and $\mathbf{3 i}$. For urea derivatives of aryl-phthalazine substituted compounds, electron withdrawing groups (nitro and fluorine) bonded on phenyl ring ( $3 \mathbf{i}$ and $\mathbf{3 l}$ ) increased the hCAs I and II inhibitory activity. In contrast, electron donating groups (methoxy, methyl) on phenyl ring (3j and $\mathbf{3 k}$ ) have moderate inhibitory activity for the hCAIs and II. For the aryl-aryl thiourea derivatives, electron donating groups as mesomeric or inductive (methoxy, methyl, and halogens) on the phenyl ring (from $\mathbf{3 b}$ to $\mathbf{3 f}$ ) have moderate inhibitory activity, but the compound (3g) with fluorine atom has good inhibition effect on hCAs I and II. Flouro substituted urea derivatives (3l and $\mathbf{3 g}$ ) showed more inhibitory effect than methoxy, methyl, chloro, and bromo substituted ureas. Fluorophenyl sulfamate adducts were reported where the sulfamates possess a rather variable binding pattern within the hCA II active site [41, 42]. Alkyl-phthalazine substituted ureas have different inhibition effects. When alkyl chain increases, inhibition effect increases with alkyl chain length due to their steric effect. It is obviously clear that bulky phthalazine group affects inhibition for the compounds.
In summary, enzyme inhibition is a more important issue for drug design and biochemical applications [43-46]. The results showed that new phthalazine substituted urea and thiourea derivatives inhibited the hCAs I and II enzyme activity. Therefore, our results suggested that the compounds are likely to be adopted as candidates to treat glaucoma and may be taken for further evaluation in in vivo studies.

\section{Acknowledgment}

This work was supported by the Research Fund of the Sakarya University, Project no. 2011-50-02-005.

\section{References}

[1] D. N. Silverman and S. Lindskog, "The catalytic mechanism of carbonic anhydrase: implications of a rate-limiting protolysis of water," Accounts of Chemical Research, vol. 21, no. 1, pp. 30-36, 1988.

[2] S. A. Zimmerman, J. G. Ferry, and C. T. Supuran, "Inhibition of the archaeal $\beta$-class (Cab) and $\gamma$-class (Cam) carbonic anhydrases," Current Topics in Medicinal Chemistry, vol. 7, no. 9, pp. 901-908, 2007. 
[3] C. T. Supuran and A. Scozzafava, "Carbonic anhydrases as targets for medicinal chemistry," Bioorganic and Medicinal Chemistry, vol. 15, no. 13, pp. 4336-4350, 2007.

[4] F. Carta, M. Aggarwal, A. Maresca et al., "Dithiocarbamates strongly inhibit carbonic anhydrases and show antiglaucoma action in vivo," Journal of Medicinal Chemistry, vol. 55, no. 4, pp. 1721-1730, 2012.

[5] C. T. Supuran, "Carbonic anhydrase inhibitors and activators for novel therapeutic applications," Future Medicinal Chemistry, vol. 3, no. 9, pp. 1165-1180, 2011.

[6] C. T. Supuran and A. Scozzafava, "Applications of carbonic anhydrase inhibitors and activators in therapy," Expert Opinion on Therapeutic Patents, vol. 12, no. 2, pp. 217-242, 2002.

[7] C. T. Supuran and A. Scozzafava, "Carbonic-anhydrase inhibitors and their therapeutic potential," Expert Opinion on Therapeutic Patents, vol. 10, no. 5, pp. 575-600, 2000.

[8] J.-P. Richalet, M. Rivera, P. Bouchet et al., "Acetazolamide: a treatment for chronic mountain sickness," American Journal of Respiratory and Critical Care Medicine, vol. 172, no. 11, pp. 14271433, 2005.

[9] C. T. Supuran, "Carbonic anhydrases: novel therapeutic applications for inhibitors and activators," Nature Reviews Drug Discovery, vol. 7, no. 2, pp. 168-181, 2008.

[10] J. A. Joule and K. Mills, Heterocyclic Chemistry at a Glance, John Wiley \& Sons, New York, NY, USA, 2012.

[11] E. C. Franklin and F. W. Bergstrom, "Heterocyclic nitrogen compounds: part II A. Hexacyclic compounds: pyridine, quinoline, and isoquinoline," Chemical Reviews, vol. 35, no. 2, pp. 77$277,1944$.

[12] C. Turk, J. Svete, B. Stanovnik et al., "Regioselective 1, 3-dipolar cycloadditions of (1Z)-1-(arylmethylidene)-5, 5-dimethyl-3oxopyrazolidin-1-ium-2-ide azomethine imines to acetylenic dipolarophiles," Helvetica Chimica Acta, vol. 84, no. 1, pp. 146156, 2001.

[13] S. Mavel, L. Thery, and A. Gueiffier, "Synthesis of imidazo[2, 1-a]phthalazines, potential inhibitors of p38 MAP kinase. Prediction of binding affinities of protein ligands," Archiv der Pharmazie Medicinal Chemistry, vol. 335, no. 1, pp. 7-14, 2002.

[14] R. W. Carling, K. W. Moore, L. J. Street et al., "3-Phenyl-6-(2pyridyl)methyloxy-1,2,4-triazolo[3,4-a]phthalazines and Analogues: high-affinity $\gamma$-aminobutyric acid-a benzodiazepine receptor ligands with $\alpha 2, \alpha 3$, and $\alpha 5$-subtype binding selectivity over $\alpha 1$," Journal of Medicinal Chemistry, vol. 47, no. 7, pp. 18071822, 2004.

[15] Y. Imamura, A. Noda, T. Imamura, Y. Ono, T. Okawara, and H. Noda, "A novel methylthio metabolite of s-triazolo[3,4a]phthalazine, a lead compound for the development of antianxiety drugs, in rats," Life Sciences, vol. 74, no. 1, pp. 29-36, 2003.

[16] J. S. Kim, H.-J. Lee, M.-E. Suh et al., "Synthesis and cytotoxicity of 1-substituted 2-methyl- $1 H$-imidazo[4,5- $g]$ phthalazine-4,9dione derivatives," Bioorganic and Medicinal Chemistry, vol. 12, no. 13, pp. 3683-3686, 2004.

[17] A. D. Lebsack, J. Gunzner, B. Wang et al., "Identification and synthesis of $[1,2,4]$ triazolo[3,4-a]phthalazine derivatives as high-affinity ligands to the $\alpha 2 \delta-1$ subunit of voltage gated calcium channel," Bioorganic and Medicinal Chemistry Letters, vol. 14, no. 10, pp. 2463-2467, 2004.

[18] P. G. Tsoungas and M. Searcey, "A convenient access to benzosubstituted phthalazines as potential precursors to DNA intercalators," Tetrahedron Letters, vol. 42, no. 37, pp. 6589-6592, 2001.
[19] R. Sivakumar, S. K. Gnanasam, S. Ramachandran, and J. T. Leonard, "Pharmacological evaluation of some new 1-substituted-4-hydroxy-phthalazines," European Journal of Medicinal Chemistry, vol. 37, no. 10, pp. 793-801, 2002.

[20] A. Coelho, E. Sotelo, N. Fraiz et al., "Pyridazines. Part 36: synthesis and antiplatelet activity of 5-substituted-6-phenyl-3(2H)pyridazinones," Bioorganic and Medicinal Chemistry Letters, vol. 14, no. 2, pp. 321-324, 2004.

[21] S. Demirayak, A. C. Karaburun, and R. Beis, "Some pyrrole substituted aryl pyridazinone and phthalazinone derivatives and their antihypertensive activities," European Journal of Medicinal Chemistry, vol. 39, no. 12, pp. 1089-1095, 2004.

[22] D. S. Doğruer, M. F. Şahin, E. Küpeli, and E. Yeşilada, "Synthesis and analgesic and anti-Inflammatory activity of new pyridazinones," Turkish Journal of Chemistry, vol. 27, no. 6, pp. 727-738, 2003.

[23] D. S. Dogruer, E. Kupeli, E. Yesilada, and M. F. Sahin, "Synthesis of new 2-[1(2H)-phthalazinon-2-yl]-acetamide and 3-[1(2H)phthalazinon-2-yl]-propanamide derivatives as antinociceptive and anti-inflammatory agents," Archiv der Pharmazie, vol. 337, no. 6, pp. 303-310, 2004.

[24] M. Sönmez, I. Berber, and E. Akbaş, "Synthesis, antibacterial and antifungal activity of some new pyridazinone metal complexes," European Journal of Medicinal Chemistry, vol. 41, no. 1, pp. 101-105, 2006.

[25] Y. Tanizaki, J. Ohtani, and I. Kimura, "Actions and crossreactivity of antiallergic agents and a calcium channel antagonist on rat peritoneal mast cells. Difference in the action mechanisms and cross-reactivity among the agents," Agents and Actions, vol. 37, no. 1-2, pp. 8-15, 1992.

[26] B. M. Groves, L. J. Rubin, and M. F. Frosolono, "A comparison of the acute hemodynamic effects of prostacyclin and hydralazine in primary pulmonary hypertension," American Heart Journal, vol. 110, no. 6, pp. 1200-1204, 1985.

[27] M. Packer, B. Greenberg, B. Massie, and H. Dash, "Deleterious effects of hydralazine in patients with pulmonary hypertension," The New England Journal of Medicine, vol. 306, no. 22, pp. 13261331, 1982.

[28] C. A. Keller, J. W. Shepard Jr., and D. S. Chun, "Effects of hydralazine on hemodynamics, ventilation, and gas exchange in patients with chronic obstructive pulmonary disease and pulmonary hypertension," American Review of Respiratory Disease, vol. 130, no. 4, pp. 606-611, 1984.

[29] F. Pacchiano, F. Carta, P. C. McDonald et al., "Ureidosubstituted benzenesulfonamides potently inhibit carbonic anhydrase IX and show antimetastatic activity in a model of breast cancer metastasis," Journal of Medicinal Chemistry, vol. 54, no. 6, pp. 1896-1902, 2011.

[30] R. Nixha, M. Arslan, Y. Atalay, N. Gençer, A. Ergün, and O. Arslan, "Synthesis and theoretical calculations of carbazole substituted chalcone urea derivatives and studies their polyphenol oxidase enzyme activity," Journal of Enzyme Inhibition and Medicinal Chemistry, vol. 28, no. 4, pp. 808-815, 2013.

[31] F. Celik, M. Arslan, E. Yavuz, D. Demir, and N. Gençer, "Synthesis and carbonic anhydrase inhibitory properties of novel 1, 4-dihydropyrimidinone substituted diarylureas," Journal of Enzyme Inhibition and Medicinal Chemistry, vol. 16, no. 1, pp. $1-5,2013$.

[32] O. Arslan, B. Nalbantoğlu, N. Demir, N. Özdemir, and Ö. İ. Küfrevioğlu, "A new method for the purification of carbonic anhydrase isozymes by affinity chromatography," Turkish Journal of Medical Sciences, vol. 26, no. 2, pp. 163-166, 1996. 
[33] T. H. Maren, "A simplified micromethod for the determination of carbonic anhydrase and its inhibitors," The Journal of pharmacology and experimental therapeutics, vol. 130, pp. 26-29, 1960.

[34] M. Sayyafi, M. Seyyedhamzeh, H. R. Khavasi, and A. Bazgir, "One-pot, three-component route to $2 H$-indazolo[2,1- $b]$ phthalazine-triones," Tetrahedron, vol. 64, no. 10, pp. 2375-2378, 2008.

[35] M. Ono, M. Haratake, H. Mori, and M. Nakayama, "Novel chalcones as probes for in vivo imaging of $\beta$-amyloid plaques in Alzheimer's brains," Bioorganic and Medicinal Chemistry, vol. 15, no. 21, pp. 6802-6809, 2007.

[36] H. Ogita, Y. Isobe, H. Takaku et al., "Synthesis and structureactivity relationship of diarylamide urea derivatives as selective inhibitors of the proliferation of human coronary artery smooth muscle cells," Bioorganic and Medicinal Chemistry, vol. 10, no. 6, pp. 1865-1871, 2002.

[37] O. Arslan, Ö. I. Küfrevioğlu, and B. Nalbantoğlu, "Synthesis and investigation of inhibition effects of new carbonic anhydrase inhibitors," Bioorganic and Medicinal Chemistry, vol. 5, no. 3, pp. 515-518, 1997.

[38] A. Maresca, C. Temperini, L. Pochet, B. Masereel, A. Scozzafava, and C. T. Supuran, "Deciphering the mechanism of carbonic anhydrase inhibition with coumarins and thiocoumarins," Journal of Medicinal Chemistry, vol. 53, no. 1, pp. 335-344, 2010.

[39] P. Ebbesen, E. O. Pettersen, T. A. Gorr et al., “Taking advantage of tumor cell adaptations to hypoxia for developing new tumor markers and treatment strategies," Journal of Enzyme Inhibition and Medicinal Chemistry, vol. 24, no. 1, pp. 1-39, 2009.

[40] A. Maresca and C. T. Supuran, "Coumarins incorporating hydroxy- and chloro-moieties selectively inhibit the transmembrane, tumor-associated carbonic anhydrase isoforms IX and XII over the cytosolic ones i and II," Bioorganic and Medicinal Chemistry Letters, vol. 20, no. 15, pp. 4511-4514, 2010.

[41] J.-Y. Winum, A. Innocenti, D. Vullo, J.-L. Montero, and C. T. Supuran, "Carbonic anhydrase inhibitors; fluorinated phenyl sulfamates show strong inhibitory activity and selectivity for the inhibition of the tumor-associated isozymes IX and XII over the cytosolic ones I and II," Bioorganic and Medicinal Chemistry Letters, vol. 19, no. 17, pp. 5082-5085, 2009.

[42] C.-Y. Kim, J. S. Chang, J. B. Doyon et al., "Contribution of fluorine to protein - Ligand affinity in the binding of fluoroaromatic inhibitors to carbonic anhydrase II," Journal of the American Chemical Society, vol. 122, no. 49, pp. 12125-12134, 2000.

[43] N. Gençer and O. Arslan, "In vitro effects of some pesticides on PON1Q192 and PON1R192 isoenzymes from human serum," Fresenius Environmental Bulletin, vol. 20, no. 3, pp. 590-596, 2011.

[44] D. Demir, N. Gencer, and A. Er, "Purification and characterization of prophenoloxidase from Galleria mellonella L.," Artificial Cells Blood Substit and Biotechnol, vol. 40, no. 6, pp. 391-395, 2012.

[45] M. Şentürk, H. A. Alici, Ş. Beydemir, and Ö. İ. Küfrevioglu, "In vitro and in vivo effects of some benzodiazepine drugs on human and rabbit erythrocyte carbonic anhydrase enzymes," Journal of Enzyme Inhibition and Medicinal Chemistry, vol. 27, no. 5, pp. 680-684, 2012.

[46] N. Gençer, A. Ergün, and D. Demir, "In vitro effects of some herbicides and fungicides on human erythrocyte carbonic anhydrase activity," Fresenius Environmental Bulletin, vol. 21, no. 3, pp. 549-552, 2012. 

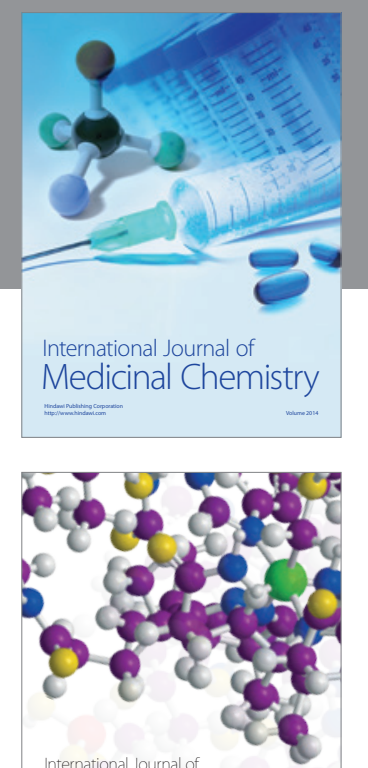

\section{Carbohydrate} Chemistry

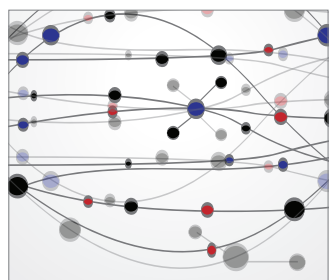

The Scientific World Journal
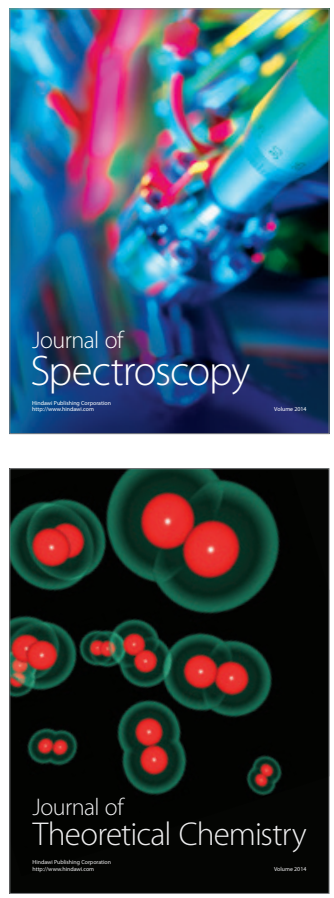
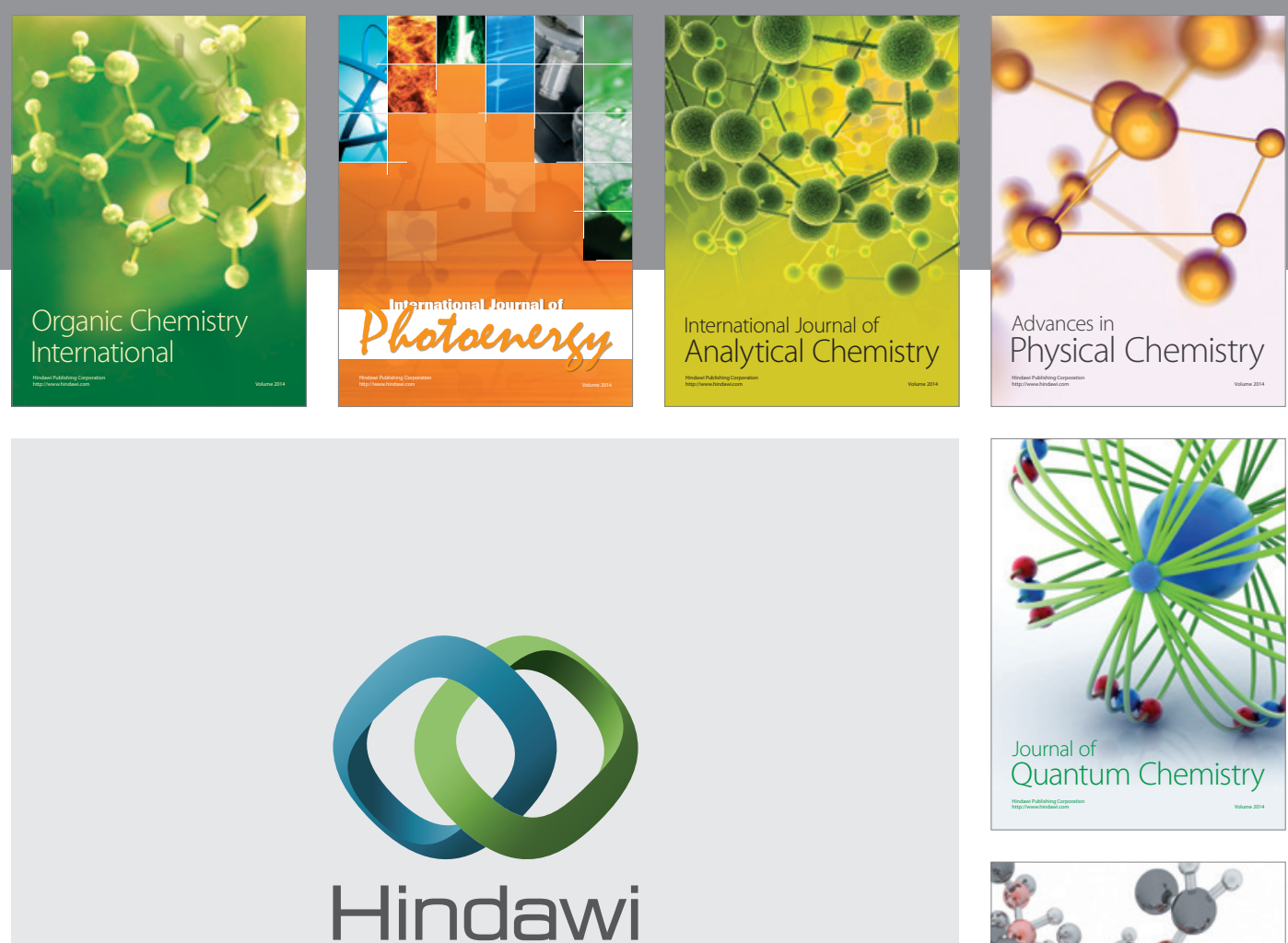

Submit your manuscripts at

http://www.hindawi.com

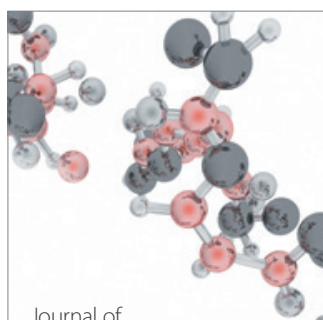

Analytical Methods

in Chemistry

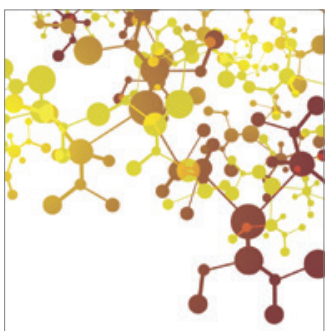

Journal of

Applied Chemistry

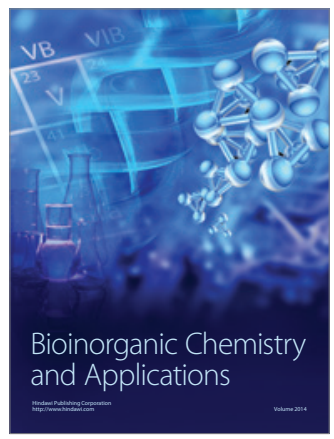

Inorganic Chemistry
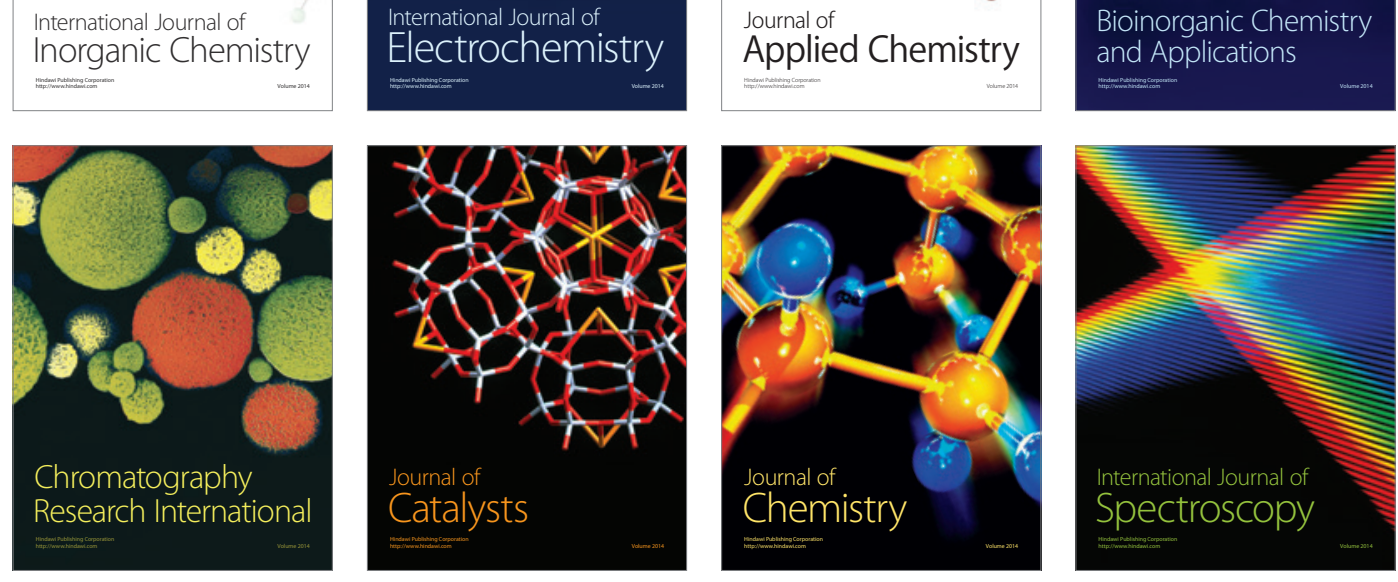